\title{
Enhanced biocatalytic sustainability of laccase by immobilization on functionalized carbon nanotubes/polysulfone membranes
}

\author{
João B. Costa ${ }^{1}$, Maria J. Lima ${ }^{1}$, Maria J. Sampaio ${ }^{1}$, Márcia C. Neves ${ }^{2}$, \\ Joaquim L. Faria ${ }^{1}$, Sergio Morales-Torres ${ }^{3 *}$, Ana P. M. Tavares ${ }^{2 *}$, \\ Cláudia G. Silva ${ }^{1 *}$
}

${ }^{1}$ Laboratory of Separation and Reaction Engineering - Laboratory of Catalysis and Materials (LSRE-LCM), Faculdade de Engenharia, Universidade do Porto, Rua Dr. Roberto Frias s/n, 4200-465 Porto, Portugal

${ }^{2}$ CICECO-Aveiro Institute of Materials, Department of Chemistry, University of Aveiro, 3810-193 Aveiro, Portugal

${ }^{3}$ Carbon Materials Research Group, Department of Inorganic Chemistry, Faculty of Sciences, University of Granada, Campus Fuentenueva s/n, 18071 Granada, Spain

*Corresponding authors: cgsilva@fe.up.pt; aptavares@ua.pt; semoto@ugr.es 


\section{Abstract}

Chemically functionalized multi-walled carbon nanotubes (CNTs) are used as carriers for laccase immobilization. In this work, CNTs were modified using different approaches with a combination of methods involving hydrothermal oxidation with nitric acid, treatment with 3-aminopropyltriethoxysilane, glutaraldehyde, N-ethyl-N(3-(dimethylamino)-propyl) carbodiimide hydrochloride and N-hydroxysuccinimide. The enzyme immobilization efficiency and recovered activity were evaluated towards 2,2'-azino-bis(3-ethylbenzathiazoline-6-sulfonic acid) biocatalytic oxidation. The best compromise between immobilization efficiency and recovered activity was obtained using the CNTs functionalized with $0.3 \mathrm{M} \mathrm{HNO}_{3}$, treated with N-ethyl-N-(3(dimethylamino)propyl) carbodiimide hydrochloride and N-hydroxysuccinimide. This catalyst also showed the best thermal stability (at 50 and $60{ }^{\circ} \mathrm{C}$ ). The bioconjugate based on this material was characterized by vibrational spectroscopies (FTIR and Raman) and by $\mathrm{N}_{2}$ adsorption. The results from reutilization tests showed that laccase activity was kept above $65 \%$ of its initial value after five consecutive cycles of reuse. The biocatalytic performance of the immobilized enzyme was evaluated for the degradation of a mixture of phenolic compounds in water containing phenol, resorcinol, 4-methoxyphenol and 4-chlorophenol. As means of cost efficient to enzyme reutilization, laccase was immobilized over polysulfone membranes blended with the functionalized CNTs and studied in the degradation of 4-methoxyphenol.

Keywords: Multi-walled carbon nanotubes (CNTs); Chemical functionalization; Laccase; Immobilization; CNTs-based polysulfone membranes; Wastewater treatment. 


\section{Introduction}

Enzyme immobilization was primarily introduced to avoid the waste of costly enzymes, allowing their reuse in many processes. Following the early attempts to produce stable systems, the applications of immobilized enzymes are continuously increasing [1]. One of the smartest uses of immobilized enzymes is their application in the treatment of wastes, including waste waters [2-6] where both the specific activity and possibility of recycle are combined for maximum performance [7].

Interestingly, carbon materials have been long preferred as carriers for enzyme immobilization, mainly because they may provide a large surface area relative to the enzyme loading. In what concerns carbon nanotubes (CNTs), their exclusive structure and properties have been intensively studied in distinct applications ranging from energy storage, biotechnology and environmental remediation [8]. Additionally, CNT surface can be easily functionalized, tuning their properties towards specific applications and enhancing their efficiency either as supports or catalysts.

The use of CNTs as supports for enzyme immobilization is reported for several applications such as bio-sensing, water remediation and biodiesel production [9-13]. CNTs present exceptional advantages when compared to traditional supports (such as silica, polymeric materials, etc.), including the large specific surface area, high adsorption capacity, and a superior enzyme loading capacity (even as compared to other carbon materials). In general, free enzymes can be destabilized or even deactivated when submitted to severe conditions of $\mathrm{pH}$ and temperature and/or in contact with organic solvents [14]. The immobilization of enzymes on solid carriers, and particularly on CNTs, is considered an effective strategy for improving the longterm operational performance, stability, shelf-storage life, selectivity, and last but not least, reusability $[12,13]$. Several approaches for enzyme immobilization on CNTs, 
including adsorption, covalent bonding, entrapment or encapsulation, have been described in the literature [15]. However, the possibility of enzyme leaching during the catalytic cycles has limited the use of immobilization techniques at laboratorial and industrial scale. Moreover, it is expected that the CNT-enzyme hybrids may present lower activity than the free form of the enzyme. Thus, the investigation on the interactions between the enzyme and the support is fundamental for the development of highly active and stable biocatalysts. Furthermore, the immobilization of enzymes in membranes may provide an increased availability of enzyme to the substrate, low leaching, prolonged lifetime, enhanced mechanical strength and reusability, among others. Functionalized CNT-based membranes have been explored mostly for the development of biosensors and for the biocatalytic treatment of contaminated water $[12,13,16]$, in particular CNT-enzyme membranes avoids the costly and timeconsuming post-separation of the biocatalyst and also allows the operation in continuous flow or multi-batch regime [5, 13, 17-19]. Polysulfone (PSf) membranes are widely used in water applications due to their excellent heat resistance and chemical stability over a large range of $\mathrm{pH}[20]$.

Laccase (EC 1.10.3.2) is a multi-copper blue oxidase enzyme found in higher plants and fungi, as well as in insects and bacteria [21, 22]. This enzyme is responsible for the oxidation of a broad range of organic and some inorganic substrates [23]. Laccase and the laccase-mediator systems have great biotechnological potential resulting from both the large variety of possible reactions and the broad substrate specificity. Potential applications include textile dye and pulp bleaching, food enhancement, bioremediation of soils and water, polymer synthesis, and development of biosensors and biofuel cells [24-27]. The principal bottlenecks of laccase-based biocatalytic processes are the low stability of the enzyme associated to 
its high cost [28]. The immobilization of laccase can be considered the best of two worlds, since the separation and reuse of this costly biocatalyst becomes possible, while maintaining, or even enhancing its catalytic activity. As mentioned above, there are already studies reporting the use of enzymes immobilized both on PSf and on CNT-based membranes [29-32]. Yet, to the best of our knowledge, the use of CNTPSf membranes for laccase immobilization has not been reported in the literature. In addition, in this work, CNT surface modification was proposed as a successful strategy to improve enzyme reuse for the removal of toxic compounds, and at the same time. For this purpose, multi-walled carbon nanotubes (CNTs) were functionalized using different techniques to promote the immobilization of laccase. The immobilization efficiency, biocatalytic activity and reusability of the resulting bioconjugates were assessed towards the oxidation of the typical laccase substrate 2,2'-azino-bis(3-ethylbenzathiazoline-6-sulfonic acid), ABTS. Finally, for the first time, the degradation of phenolic compounds in water was carried out using the best performing CNT-laccase bioconjugate both in powder form and incorporated on PSf membranes.

\section{Experimental}

\subsection{Materials, enzyme and chemicals}

Multi-walled CNTs were obtained from Shenzhen Nanotechnologies Co. Ltd. (purity $\geq 95 \% ; 10-20 \mathrm{~nm}$ diameter; 5-15 $\mu \mathrm{m}$ length; ash content $\leq 0.2 \mathrm{wt} \%$, amorphous carbon $<3 \%$ : surface area $=73 \mathrm{~m}^{2} \mathrm{~g}^{-1}$ ). Commercial laccase (Novozym ${ }^{\circledR}$ 51003; 1000 LAMU/g), obtained from genetically modified Aspergillus oryzae, was kindly donated by Novozymes (Denmark). SDS-PAGE analysis of the enzyme is shown as Supplementary Information, Fig. SI1. 2,2'-azino-bis(3- 
ethylbenzathiazoline-6-sulfonic acid) (ABTS, 98\%), (3-aminopropyl)triethoxysilane (APTES, 99\%), 1-ethyl-3-(3-dimethylaminopropyl)carbodiimide hydrochloride (EDC, $\geq 98 \%)$, nitric acid $\left(\mathrm{HNO}_{3}, \geq 65 \%\right)$, tetrahydrofuran (THF, $\left.\geq 99.9 \%\right)$, phenol $(\mathrm{PH}, \geq 99 \%)$, resorcinol (RS, 99\%) polyvinylpyrrolidone (PVP, $10 \mathrm{kDa}), 1$ methyl-2-pyrrolidinone (NMP, 99.5\%) and 4-chlorophenol (CP, $\geq 99 \%)$ were purchased from Sigma-Aldrich. Glutaraldehyde (30\%) was obtained from Merck. Thionyl chloride $\left(\mathrm{SOCl}_{2}, \geq 99.0 \%\right)$ and 4-methoxyphenol (MP, $\geq 98 \%$ ) were purchased from Fluka. N-hydroxysuccinimide (NHS, 98\%) was obtained from Alfa Aesar. Polysulfone Udel ${ }^{\circledR}$ P-3500 LCD MB3 polymer was kindly supplied in pellet form by Solvay.

\subsection{CNTs chemical functionalization}

\subsubsection{Liquid-phase oxidation}

Hydrothermal oxidation of the pristine CNTs was performed in a Teflon-lined stainless steel autoclave using $\mathrm{HNO}_{3}$ aqueous solutions with variable concentrations $(0.05,0.10,0.20$ and $0.30 \mathrm{M})$ at $200{ }^{\circ} \mathrm{C}$, as described elsewhere [33]. Briefly, $0.2 \mathrm{~g}$ of CNTs was added to $75 \mathrm{~mL}$ of a $\mathrm{HNO}_{3}$ aqueous solution. After being sealed, the vessel was put into an oven at $200{ }^{\circ} \mathrm{C}$ for $2 \mathrm{~h}$. Then, the CNTs were recovered, rinsed with water until neutrality, and dried overnight at $120^{\circ} \mathrm{C}$. The resulting materials were labelled as CNTox-Y, where $\mathrm{Y}$ corresponds to the $\mathrm{HNO}_{3}$ concentration (in $\mathrm{M}$ ) used in the oxidation treatment $(\mathrm{Y}=0.050,0.10,0.20$ and 0.30$)$. These materials were used for the subsequent chemical functionalization.

\subsubsection{Silanization and addition of cross-linkers}


For the treatment with glutaraldehyde (crosslinker), $4.0 \mathrm{mg}$ of CNTox-Y samples were added to $0.75 \mathrm{~mL}$ of a $5 \%$ glutaraldehyde solution in $50 \mathrm{mM}$ phosphate buffer $(\mathrm{pH}$ 7.0). The suspension was stirred for $2 \mathrm{~h}$ at room temperature and then centrifuged and washed with buffer. Materials were labelled as CNTox-Y-G.

Silanization of CNTox-Y surface was performed by adding $0.1 \mathrm{~g}$ of CNTox to $15 \mathrm{~mL}$ of a $1 \%$ aqueous solution of APTES. The suspension was left under stirring for $24 \mathrm{~h}$ at $50{ }^{\circ} \mathrm{C}$. After this step, the nanotubes were filtered, washed with water, and dried overnight at $100^{\circ} \mathrm{C}$. The resulting materials were designated as CNTox-Y-A.

A combination of the two above-mentioned treatments was also performed, i.e. silanization and then addition of a crosslinker (CNTox-Y-AG samples).

Finally, the treatment of CNTox-Y with EDC (as crosslinker) and NHS (as stabilizer) was also performed and materials were labeled as CNTox-Y-EN. Briefly, $4.0 \mathrm{mg}$ of CNTox-Y was added to $1.5 \mathrm{~mL}$ of a buffer solution (50 mM phosphate buffer; $\mathrm{pH}$ 8.0) containing $40 \mathrm{mg} \mathrm{L}^{-1}$ of NHS and $20 \mathrm{mg} \mathrm{L}^{-1}$ of EDC. The suspension was stirred for $1 \mathrm{~h}$. Then, the modified CNTs were centrifuged and washed twice with the buffer solution.

\subsection{Preparation of polysulfone membranes}

Polyssulfone (PSf) membranes blended with CNTs oxidized with $0.3 \mathrm{M} \mathrm{HNO}_{3}$ were prepared by a non-solvent induced phase separation method similar to that reported elsewhere [20]. In a standard procedure, different amounts of CNTs $(0.1,0.3$ and 0.5 wt.\%) were dispersed in $30 \mathrm{~mL}$ of NMP until achieving a uniform distribution, then polyvinylpyrrolidone (PVP) 2 wt.\% and PSf polymers $12 \mathrm{wt} . \%$ were added to the resulting NMP dispersion at $70^{\circ} \mathrm{C}$ for $2 \mathrm{~h}$. After that, the dope was cooled down and casted on a glass dish through spin-coating (SPSf-Europe, SPIN 
150) and subsequently, immersed into a distilled water coagulation bath at room temperature to form the corresponding membranes, which were stored in a distilled water bath until being used. A neat PSf membrane without any amount of CNTs (referred as M) was also prepared following the same experimental procedure. PSf membranes were labelled as follows: $\mathrm{z}-\mathrm{CNT} / \mathrm{M}$, where $\mathrm{z}$ is the amount of functionalized CNTs used (ranging from 0.1 to $0.5 \mathrm{wt} . \%$ ).

\subsection{Characterization techniques}

The surface area of the materials was determined by $\mathrm{N}_{2}$ adsorption-desorption at $-196^{\circ} \mathrm{C}$, measured on a Quantachrome NOVA 4200e apparatus. Samples were first degassed in vacuum for $3 \mathrm{~h}$ at $120{ }^{\circ} \mathrm{C}$ before analysis. The Brunauer-Emmett-Teller (BET) specific surface area $\left(S_{B E T}\right)$ was determined from the nitrogen adsorption data within the $0.05-0.15$ range of relative pressure. Fourier transform infrared (FTIR) analysis was carried out on a FT-IR Nicolet 510-P spectrometer (Thermo Fisher Scientific, USA) equipped with a MIRacle ${ }^{\mathrm{TM}}$ Single Attenuated Total Reflectance (ATR) ZnSe crystal plate accessory (PIKE Technologies, USA). Raman spectra were recorded in a Brucker RFS100/S FT-Raman spectrometer (Nd:YAG laser, $1064 \mathrm{~nm}$ excitation), at a power of $200 \mathrm{mV}$, with 3000 scans at a resolution of $4 \mathrm{~cm}^{-1}$. A JEOL 2010F analytical electron microscope, equipped with a field-emission gun was used for transmission electron microscopy (TEM) images.

The morphology of PSf membranes was characterized by scanning electron microscopy (SEM) using a FEI Quanta 400FEG ESEM/EDAX Genesis X4M instrument. The membranes were frozen and broken under liquid nitrogen. The microscope was equipped with a special multiple sample holder, in which the broken membranes were vertically positioned to cross-sectional analysis. 


\subsection{Laccase immobilization over CNTs and CNTs/PSf membranes}

Enzyme immobilization was carried out by adding $4.0 \mathrm{mg}$ of CNTs to $1.2 \mathrm{~mL}$ of a $3.75 \mu \mathrm{L}_{\text {lac }} \mathrm{mL}^{-1}$ laccase solution in $50 \mathrm{mM}$ phosphate buffer (pH 8.0), under orbital stirring for $2 \mathrm{~h}$ at $25^{\circ} \mathrm{C}$. The $\mathrm{pH}$ of immobilization (pH 8.0) was chosen based in preliminary studies on the effect of this parameter in the activity of free laccase (see Supplementary Information, Fig. SI2). The activity of the laccase stock solution, determined by using ABTS as substrate, was $1600 \mathrm{U} \mathrm{mL}^{-1}$. After immobilization, CNTs were washed several times with the appropriated buffer. Control tests for enzyme leaching were carried out by measuring the enzyme activity in the buffer after washing CNTs. No enzyme activity was detected for all materials used. Immobilization yield (\%) is defined as the difference in activity of the free enzyme in solution and the activity of the free laccase remaining in the supernatant after immobilization, divided by the activity of the enzyme in the free form times $100 \%$. Immobilization of laccase over CNTs/PSf membranes was carried out by immersing the prepared membranes (area of $5 \mathrm{~cm}^{2}$ ) in $20 \mathrm{~mL}$ of laccase solution (buffered with phosphate, $\mathrm{pH} \mathrm{8.0)} \mathrm{for} 1 \mathrm{~h}$ at $25^{\circ} \mathrm{C}$. Finally, the membranes were washed 3 times with the same phosphate buffer.

\subsection{Enzyme activity tests for free and immobilized laccase}

Free laccase activity was determined spectrophotometrically (JASCO V-560 UV-Vis spectrophotometer) for the oxidation of $0.4 \mathrm{mM}$ ABTS substrate in $(0.05$ $\mathrm{mM}$ citrate/0.1 mM-phosphate-buffer) at $\mathrm{pH} 4.5$. The quantification of activity was determined by incubating $0.1 \mathrm{~mL}$ of the enzyme solution mixed with $1.9 \mathrm{~mL}$ of the ABTS solution (to a $2.0 \mathrm{~mL}$ total volume) at $40.0{ }^{\circ} \mathrm{C}$ [34]. ABTS oxidation was 
followed by measuring the increase in the absorbance at $420 \mathrm{~nm}\left(\varepsilon_{420 \mathrm{~nm}}=36000 \mathrm{M}^{-1}\right.$ $\mathrm{cm}^{-1}$ ). The change in absorbance of the solution in the cuvette was automatically measured for 1 min in kinetic mode using a JASCO V-560 UV-Vis spectrophotometer. The enzyme activity was obtained from the slope of the initial linear portion of the kinetic curve (Absorbance vs time). One unit (U) of enzyme activity was defined as the amount of laccase required to oxidize $1 \mu \mathrm{mol}$ of ABTS per minute. For the free enzyme system, the activities were expressed in $\mathrm{UL}^{-1}$.

To measure laccase activity when using immobilized enzyme, the modified CNTs or CNTs/PSf membranes were mixed with $105 \mathrm{~mL}$ of citrate/phosphate buffer $0.05 \mathrm{M} / 0.1 \mathrm{M}, \mathrm{pH} 4.5$ at $40{ }^{\circ} \mathrm{C}$ and $37.5 \mathrm{~mL}$ of ABTS $0.4 \mathrm{mM}$, under magnetic stirring at $100 \mathrm{rpm}$. Samples were filtered with $0.45 \mu \mathrm{m}$ polypropylene filters with exception of CNTs/PSf membranes, where filtration was not needed. The enzyme activity was determined using the following expression:

$$
\frac{U}{g}=\frac{A_{\min } \times f_{d i l} \times V_{r x n} 10^{6}}{\varepsilon_{420 n m} \times m_{C N T}}
$$

where, $\mathrm{U} / \mathrm{g}$ is the amount of enzyme capable to oxidize $1 \mu \mathrm{mol}$ of ABTS (per minute and per mass unit of CNTs); $A_{\min }$ is the absorbance per minute (determined by linear regression); $f_{\text {dil }}$ is the dilution factor; $V_{r x n}$ is the volume of reaction (in $\left.\mathrm{mL}\right) ; 10^{6}$ is the conversion factor of $\mathrm{M}$ into $\mu \mathrm{M}$; $\varepsilon_{420 \mathrm{~nm}}$ is the ABTS molar absorption coefficient; and $m_{C N T}$ is the amount of CNTs, either in powder form or immobilized into membranes (in grams of CNT in the membrane, not the total mass of membrane).

\subsection{Thermal stability of free and immobilized laccase}


Thermal stability studies were performed by incubating the free and immobilized enzyme in phosphate buffer $(100 \mathrm{mM}, \mathrm{pH}$ 8.0) at different temperatures $\left(40-60{ }^{\circ} \mathrm{C}\right)$. Samples of the enzyme solution and of CNTs-laccase bioconjugate were kept in a temperature-controlled water bath. A sample was taken regularly, and the enzymatic activity was immediately determined according to the above-described methods

The thermal parameters were determined following a simplified deactivation model $[35,36]$ :

$$
\begin{gathered}
E \stackrel{k_{1}}{\rightarrow} E_{1} \stackrel{k_{2}}{\rightarrow} E_{2} \\
A=\left[100+\frac{\alpha_{1} k_{1}}{k_{2}-k_{1}}-\frac{\alpha_{2} k_{2}}{k_{2}-k_{1}}\right] e^{-k_{1} t}+\left[\frac{\alpha_{2} k_{1}}{k_{2}-k_{1}}-\frac{\alpha_{1} k_{1}}{k_{2}-k_{1}}\right] e^{-k_{2} t}+\alpha_{2}
\end{gathered}
$$

where $A$ is the relative residual enzyme activity, $\alpha_{1}$ and $\alpha_{2}$ are the ratios of specific activities (remaining activities) to the different states $E_{1} / E$ and $E_{2} / E$ (see Eq. 2), respectively, $k_{1}$ and $k_{2}$ are the thermal inactivation rate constants and $t$ is the incubation time. The experimental results suggest that laccase undergoes a conformational transition when submitted to high temperatures, the inactivation following a single exponential decay, in which $\alpha_{2}=0$ and $k_{2}=0$ :

$$
A=(100-\alpha) e^{-k t}+\alpha
$$

The thermal parameters $\alpha$ and $k$ were determined by non-linear fitting over the experimental data. The biocatalyst half-life $\left(t_{1 / 2}\right)$ was calculated from Eq. 4 , using the 
estimated parameters $(k$ and $\alpha)$ and taking $A$ as one-half of $A_{0}$, the initial residual enzyme activity.

\subsection{Operational stability of immobilized laccase}

To investigate the reuse of the immobilized enzyme, the CNTs-laccase bioconjugates were tested for ABTS oxidation and then, the material was recovered by filtration and thoroughly washed with buffer solution. Then, it was added to a fresh substrate solution, and the biocatalytic activity determined. The activity of the immobilized enzyme after the first reaction cycle was used as reference (corresponding to $100 \%$ ) and the activities obtained in the 4 subsequent cycles were compared to that value.

\subsection{Biocatalytic degradation of phenolic compounds by laccase}

The degradation of a mixture of phenolic compounds containing phenol, resorcinol, 4-methoxyphenol and 4-chlorophenol was evaluated using free laccase and the enzyme immobilized into CNT-0.30-EN. In these reactions ABTS was used as mediator. The reaction solution $(20 \mathrm{~mL})$, containing a mixture of the phenolic compounds (with a concentration of $10 \mathrm{mg} \mathrm{L}^{-1}$ in each component), laccase $1 \mu \mathrm{L} \mathrm{mL}^{-1}$ (free enzyme) or $1 \mathrm{mg} \mathrm{mL}^{-1}$ (immobilized enzyme) and ABTS $(0.1 \mathrm{mM})$, was magnetically stirred for $60 \mathrm{~min}$. A similar procedure was adopted for the reactions using the enzyme immobilized over CNTs/PSf membranes. In this case, the biocatalytic tests were performed for the degradation of 4-methoxyphenol (MP) in the absence of any mediator. Reactions were carried out in triplicate and data are expressed as the average of three independent assays. 
Samples were periodically withdrawn, and the concentration of each compound was determined by high performance liquid chromatography (HPLC) using a Hitachi Elite LaChrom apparatus equipped with L-2450 diode array detector and a Purospher Star RP-18 endcapped column $(250 \mathrm{~mm} \times 4.6 \mathrm{~mm}, 5 \mu \mathrm{m}$ particles $)$ working at room temperature. The mobile phase consisted in a mixture of water (W): methanol (M), with proportions varying from (70:30) to (47:53) in 16 min at a flow rate of $1 \mathrm{~mL} \mathrm{~min}{ }^{-1}$. The initial conditions were reset in a $1 \mathrm{~min}$ gradient step and the W:M (70:30) mixture was eluted for 6 min before starting the next analysis.

\section{Results and discussion}

\subsection{Materials characterization}

Surface interactions between the enzyme and the support were investigated by vibrational spectroscopy, carrying out FTIR-ATR analyses of selected materials, namely pristine CNTs, CNTox-0.30, CNTox-0.30-EN and laccase immobilized over CNTox-0.30-EN. As expected, the vibrational structure of the surface is significantly changed as new bands appear in the infrared spectrum after oxidation of CNTs with $\mathrm{HNO}_{3}$. The intensity of the new occurring bands increases with the concentration of acid solution used in the liquid phase treatment (Fig. 1a). Four main groups of bands can be observed in the FTIR spectrum of CNTox-0.30 (Fig. 1a) attributed to oxygenated groups: i) a band at $1800 \mathrm{~cm}^{-1}$ attributed to the $\mathrm{C}=\mathrm{O}$ stretching vibration of carboxylic acids ii) a peak at $1630 \mathrm{~cm}^{-1}$, due to vibration of $\mathrm{O}-\mathrm{H}$ bonds of adsorbed water [37]; iii) a broad band centered at $1400 \mathrm{~cm}^{-1}$ assigned to $\mathrm{O}-\mathrm{H}$ bending in phenols and carboxylic acids; iv) a set of bands in the region $1200-1020 \mathrm{~cm}^{-1}$ assigned to the $\mathrm{C}-\mathrm{O}$ stretching vibration in phenols. An additional band peaking at $880 \mathrm{~cm}^{-1}$ can be ascribed to isolated aromatic $\mathrm{C}-\mathrm{H}$ out-of-plane bending vibrations. 

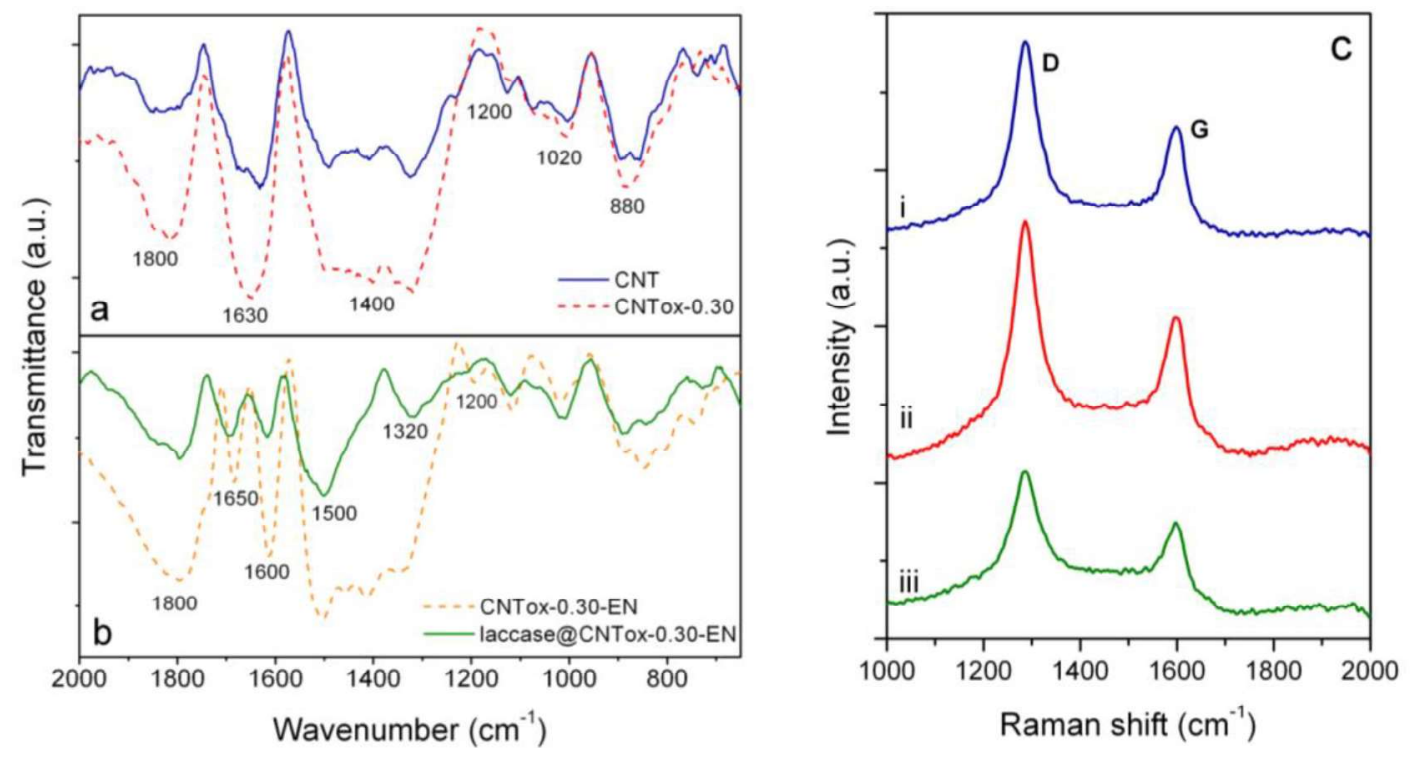

Figure 1. FTIR-ATR spectra of: (a) CNT and CNTox-0.30; (b) CNTox-0.30-EN and laccase immobilized on CNTox-0.30-EN. (c) Raman spectra of pristine CNT (i), CNTox-0.30-EN (ii) and laccase immobilized on CNTox-0.30-EN (iii).

After treatment with EDC/NHS the $1630 \mathrm{~cm}^{-1}$ band splits in two new bands, at $1600 \mathrm{~cm}^{-1}$ and $1650 \mathrm{~cm}^{-1}$, respectively (Fig. 1b). These bands are related to peptide $\mathrm{C}=\mathrm{O}$ stretch and peptide $\mathrm{N}-\mathrm{H}$ bend, respectively, typical from the amide signature in the infrared spectra [38]. The band at c.a. $1200 \mathrm{~cm}^{-1}$ refers to $\mathrm{C}-\mathrm{N}$ vibration of amide group. In addition, an increase in the intensity of the band at $1800 \mathrm{~cm}^{-1}$ indicates the attachment of the succinimidyl ester (-COOsuc) termination on the material surface. This intense band is the result of the overlap of different peaks, namely at $1820 \mathrm{~cm}^{-1}$ related to - COOsuc carbonyl stretch, at $1785 \mathrm{~cm}^{-1}$, attributed to the suc-cycle $\mathrm{C}=\mathrm{O}$ symmetric stretch and at $1745 \mathrm{~cm}^{-1}$ corresponding to suc-cycle $\mathrm{C}=\mathrm{O}$ antisymmetric stretch, as previously described in the literature [38]. These results confirm the successful functionalization of CNTox-0.30 with EDC/NHS. 
After laccase immobilization, a decrease in the intensity of the bands at 1600 $\mathrm{cm}^{-1}, 1650 \mathrm{~cm}^{-1}$ and at $1200 \mathrm{~cm}^{-1}$ suggests that the enzyme bounds to amide terminal groups of the CNTs functionalized with EDC/NHS (Fig. 1b). Furthermore, the appearance of two new bands, one at $1320 \mathrm{~cm}^{-1}$, due to $\mathrm{C}-\mathrm{N}$ stretching vibration of amines, and another at $1500 \mathrm{~cm}^{-1}$, ascribed to ring stretching vibration of side chain aromatic amino acids, is indicative of the presence of laccase on the surface of CNTox-0.30-EN $[9,39]$.

The Raman spectra of pristine CNTs, CNTox-0.30-EN and laccase modified CNTox-0.30-EN (Fig. 1c) exhibit two characteristic main bands in the 1000-2000 $\mathrm{cm}^{-1}$ region. The first order $\mathrm{G}$ mode peaking at c.a. $1600 \mathrm{~cm}^{-1}$ is ascribed to the regular $\mathrm{sp}^{2}$ graphitic network of CNTs, while the D mode band at $1287 \mathrm{~cm}^{-1}$ results from the disorder and defects in the carbon lattice [40]. The ratio between the intensities of $\mathrm{D}$ and $\mathrm{G}$ bands $\left(\mathrm{I}_{\mathrm{D}} / \mathrm{I}_{\mathrm{G}}\right)$ may be used to assess the degree of purity and the existence of defect sites as well as the extent of CNTs functionalization [41]. The $\mathrm{I}_{\mathrm{D}} / \mathrm{I}_{\mathrm{G}}$ values observed for pristine CNTs, CNTox-0.30-EN and laccase modified CNTox-0.30-EN were $1.55,1.66$ and 2.81 , respectively. This increase in the $\mathrm{I}_{\mathrm{D}} / \mathrm{I}_{\mathrm{G}}$ ratio upon functionalization of CNTs with the cross linker and the enzyme indicates an increase in the disorder of the CNTs' surface due to the covalent immobilization of laccase [42].

The morphological analysis of PSf membranes blended with functionalized CNTs (i.e., CNT/M) and the neat PSf membrane (M) was carried out by SEM. Fig. 2 shows representative images of the top surfaces and cross-sections at different magnifications. In general, all membranes presented an asymmetric structure with a similar dense top surface and a porous sub-layer. The incorporation of different amounts of functionalized CNTs did not influence significantly the morphology of the 
membrane surface (Figs. 2a, d and g), but a more porous structure with elongated finger-like pores was obtained observed across the CNT/M membranes regardless the amount of functionalized CNTs, according the cross-section micrographs (Figs. 2b-c vs. e-f and g-i). In addition, functionalized CNTs were homogenously dispersed throughout the polymer structure even at high loadings (as confirmed by visual analysis, see Supplementary Information, Fig. SI3), although some isolated CNT bundles were also found through the finger-like pores of the membranes (Fig. $2 \mathrm{i}$ for 0.5-CNT/M). These results suggest that the chemical functionalization of CNTs improved a fast solvent/non-solvent exchange during phase inversion of the membranes, favoring the formation of this type of pores [20].

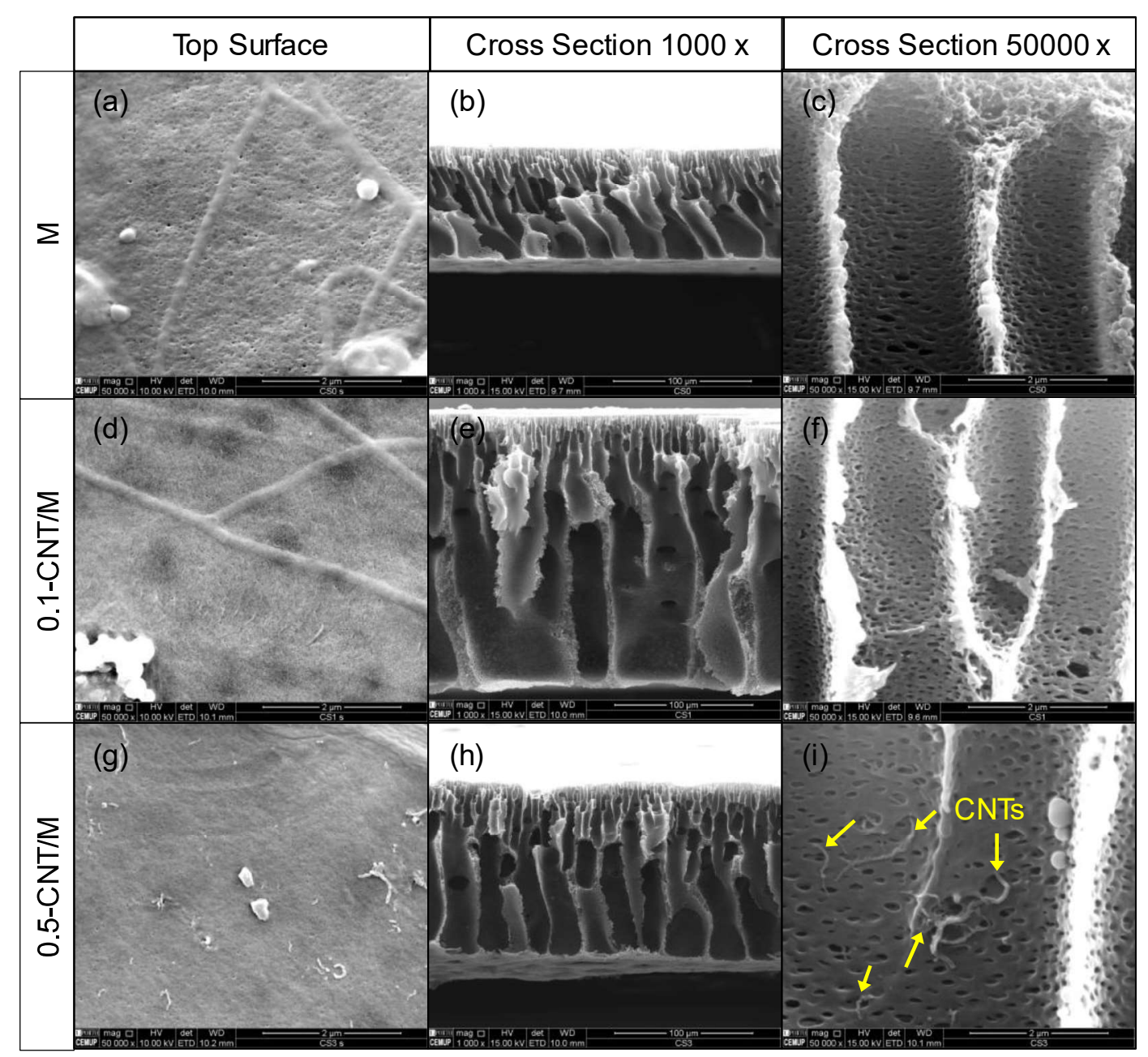


Figure 2. SEM images of the (a, d and g) top surface and (b-c, e-f, and h-i) crosssection of the neat PSf membrane (a-c) and functionalized CNT/M membranes (d-i).

\subsection{Laccase immobilization and catalytic activity on functionalized CNTs}

The CNTs have proved their capacity to act as carriers of a great variety of compounds and biomolecules including enzymes [43]. Adsorption of enzymes into CNTs occurs through different types of processes including electrostatic or hydrophobic interactions [44], hydrogen bonding and $\pi-\pi$ interactions [43]. The nature and intensity of such interactions depends on both the enzyme's structure and the surface chemistry of the CNTs. Liquid phase oxidation using $\mathrm{HNO}_{3}$ is known as an efficient method for introducing oxygen groups at the surface of carbon materials $[9,45,46]$. Depending on the concentration of the acid, different amounts of oxygencontaining groups such as carboxylic acids, phenols, quinones and carbonyl groups, can be introduced. In this work, CNTs were oxidized with $\mathrm{HNO}_{3}$ concentrations ranging from 0.05 to $0.30 \mathrm{M}(\mathrm{CNTox}-\mathrm{Y})$.

The laccase immobilization yield over the functionalized CNTs was found to increase with $\mathrm{Y}$, reaching a maximum value of $96 \%$ for CNTox-0.30 (Fig. 3a). Carboxylic acids are expected to be the predominant functionalities introduced at the surface of CNTs throughout oxidation with $\mathrm{HNO}_{3}[46,47]$. Therefore, an increase in the acidity of CNT surface and a decrease of the $\mathrm{pH}_{\mathrm{PZC}}$ to very low values is expected upon treatment of the carbon materials with increasing $\mathrm{HNO}_{3}$ concentration. Since the immobilization of the enzyme was performed at $\mathrm{pH} 8.0$, the surface of the CNTox-Y materials is expected to be negatively charged. Moreover, as the isoelectric point of laccase occurs at $\mathrm{pH} 4.2$ [48], the molecule is also negatively charged during the immobilization step. Thus, electrostatic interactions are not likely to be the main 
driving force for the immobilization of laccase into CNTox under the used conditions. In this case, laccase immobilization may be attributed to hydrophobic and $\pi-\pi$ stacking interactions between the enzyme and the carbon substrate. In addition, the treatment with $\mathrm{HNO}_{3}$ is known to create defects in the walls and to open up the end caps of the CNTs, leading to an increase in the porosity [49]. In fact, a progressive increase in the $\mathrm{S}_{\mathrm{BET}}$ of CNTox was observed when treating the original CNTs with increasing concentrations of $\mathrm{HNO}_{3}\left(\mathrm{~S}_{\mathrm{BET}}=73 \mathrm{~m}^{2} \mathrm{~g}^{-1}\right.$ and $83 \mathrm{~m}^{2} \mathrm{~g}^{-1}$ for pristine CNT and CNTox-0.30, respectively), leading to a higher adsorption capacity of the treated CNTs (14\% increase, in this case).

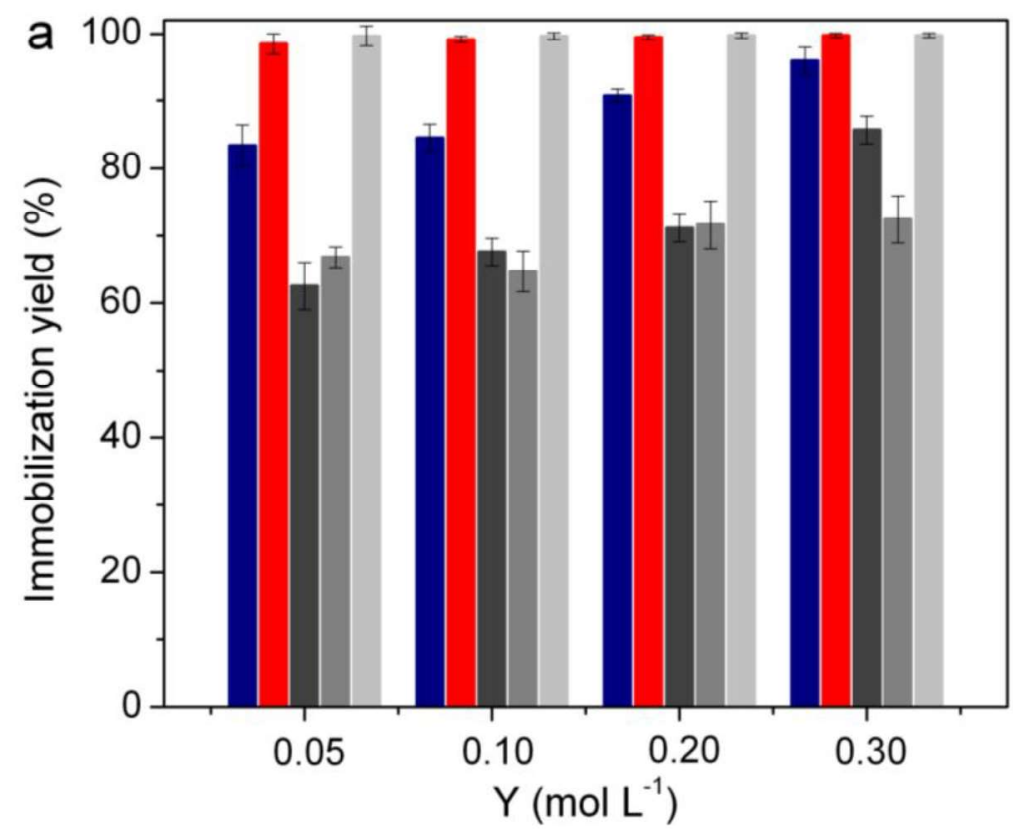




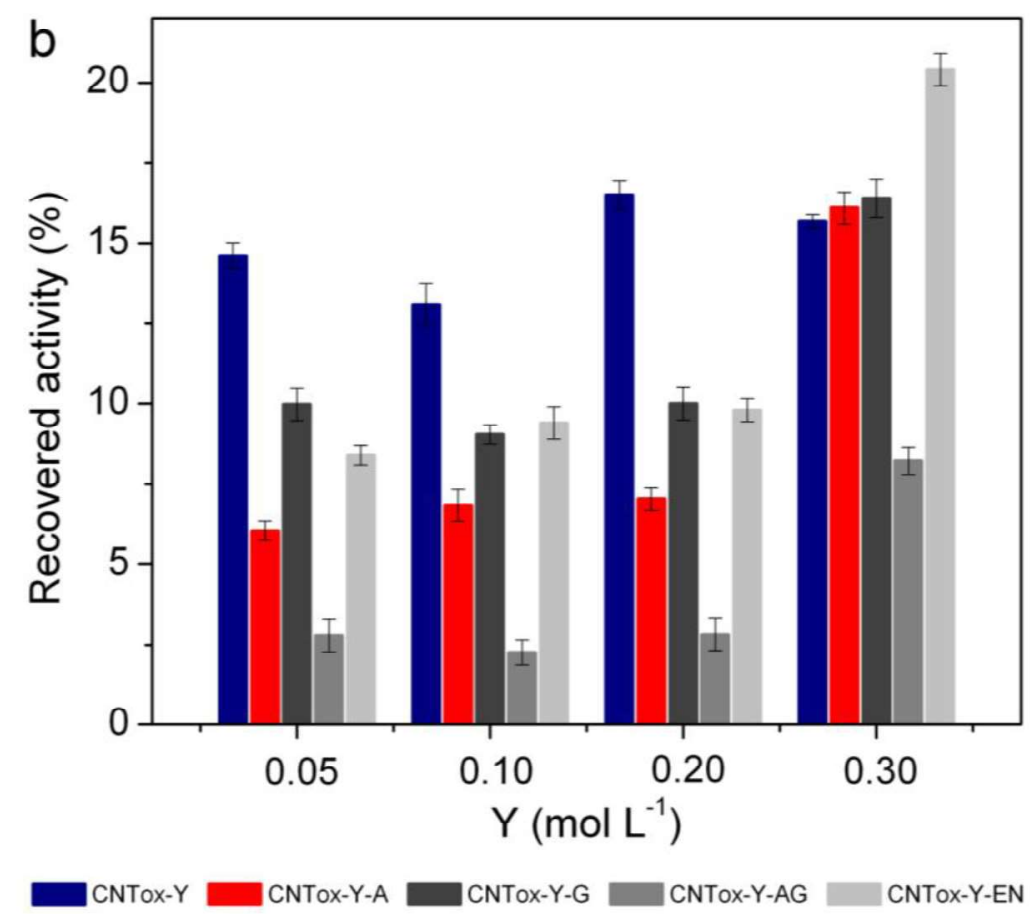

Figure 3. Laccase immobilization efficiency (a), and recovered activity (b), as a function of $\mathrm{HNO}_{3}$ concentration (Y) for surface modified CNTs. Experimental conditions: laccase immobilized in $50 \mathrm{mM}$ phosphate buffer $(\mathrm{pH} 8.0)$ under orbital stirring for $2 \mathrm{~h}$ at $25^{\circ} \mathrm{C}$.

The silanization of CNTox-Y was performed by treating the materials with APTES. In this case, the $\mathrm{OH}$ groups present at the surface of CNTox act as anchoring spots for APTES. This procedure resulted in a laccase immobilization yield above 98\% using all CNTox-Y-A materials regardless the $\mathrm{HNO}_{3}$ concentration used for oxidizing CNTs (Fig. 3a). This result can be rationalized by the simultaneous action of APTES as anchoring agent and also as spacer between the surface of neighbor CNTs, allowing steric freedom to the biomolecule during the immobilization step [50]. In addition, direct laccase adsorption on the surface of CNTox-Y may also occur, contributing for this improvement in the immobilization yield.

Glutaraldehyde activation of supports is one of the most common techniques for immobilizing enzymes [51-53]. In this method, the enzyme is immobilized mostly 
through the amine groups either $\varepsilon$-amine groups of lysine residues or terminal groups [54]. In the present work, the CNTox-Y materials treated with glutaraldehyde, resulted in CNTox-Y-G materials displaying a lower immobilization capacity compared to the parent. For example, it was observed a decrease in laccase immobilization yield from $96.0 \%$ to $85.7 \%$ by comparing the performance of CNTox0.30 to CNTox-0.30-G. A possible reason for this decrease is the blockage of CNToxY surface by glutaraldehyde molecules. Similar immobilization yield was obtained for CNTox-Y-G materials with Y between 0.05 and $0.10 \mathrm{~mol} \mathrm{~L}^{-1}$, and a relatively higher efficiency was observed for the material treated with $\mathrm{HNO}_{3} 0.30 \mathrm{~mol} \mathrm{~L}$, , probably due to a higher amount of glutaraldehyde present at the surface of CNTox-Y-0.30.

Another technique used for improving the immobilization of enzymes into solid carriers is the combination of APTES with glutaraldehyde. In this case, the previously prepared CNTox-Y-A materials, which have free amino-groups on their surface, were post-treated with glutaraldehyde yielding CNTox-Y-AG. In this case coupling glutaraldehyde to CNTox-Y-A didn't provide any positive effect in the immobilization of laccase (Fig. 3a), which may be ascribed to the obstruction of part of laccase anchorage centers by glutaraldehyde molecules. Here, it is expected that most of the enzyme may be covalently bonded to CNTs. The highest immobilization yield (72.4\%) using this series of materials was obtained using CNTox-0.3-AG.

Finally, the covalent immobilization of laccase into CNTs was attempted by the modifying the surface of the carbon materials with EDC and NHS (CNTox-YEN). EDC is a zero-length cross-linker widely used in protein conjugations. EDC reacts with a carboxylic acid group at the surface of the support, forming an aminereactive $O$-acylisourea intermediate which subsequently reacts with an amine group of the enzyme to produce a stable amide bond. Yet, this intermediate is highly 
unstable and can be easily hydrolyzed. NHS is normally used as stabilizer, converting the $O$-acylisourea intermediate into an amine-reactive ester, thus increasing the coupling efficiency $[55,56]$. CNTox-Y-EN materials show excellent capacity (c.a. $100 \%$ ) for laccase immobilization, regardless the $\mathrm{HNO}_{3}$ concentration used for oxidizing CNTs (Fig. 3a).

In terms of recovered activity, the best results (15.0\%) were in general obtained for the CNTox-Y materials in which the enzyme is immobilized by direct adsorption (Fig. 3b). For this series of materials, although the enzyme may be more active, the enzyme-support bond is expected to be weaker, which may be a drawback in what concerns reutilization. In spite of total enzyme immobilization achieved with CNToxY-A, the recovered activity was in general low, especially for $\mathrm{Y}$ between 0.05 and 0.20. Despite the lower amount of laccase immobilized into CNTox-Y-G, the recovered activity was slightly higher than that achieved using the analogous CNToxY-A materials.

The activity of laccase immobilized into CNTox-Y-AG was in general very poor. The best result was obtained for the material prepared with the CNTs oxidized with the $0.30 \mathrm{M} \mathrm{HNO}_{3}$ concentration (CNTox-0.30-AG), resulting in merely $8.3 \%$ of recovered activity. As the recovered activity was so low, laccase immobilized into CNTox-Y-AG was discarded for further studies. Besides the high immobilization yield, multiple attachments with groups from the active site of the enzyme may lead to a loss of activity.

In general, the best results in terms of recovered activity were obtained using laccase immobilized in CNTox-0.30, which strengthens the importance of the oxidation of the surface of CNTs for an improved efficiency as laccase carrier. Among all the materials tested for laccase immobilization, the highest value of 
recovered activity (20.5\%) was obtained with CNTox-0.30-EN. In this case it is expected that most of the enzyme is covalently bonded to the support, as suggested by FTIR-ATR analysis (Fig 1b), improving its stability and catalytic performance.

\subsection{Thermal stability of free and immobilized laccase}

It is generally accepted that the immobilization of enzymes may provide a protecting effect against enzyme deactivation following temperature increase. The immobilization process could affect the conformational flexibility of enzymes, resulting in an increase in enzyme rigidity. Submitting enzymes to progressively increasing temperature is one of the strategies for evaluating the changes in protein structure and enzyme stability towards denaturation resulting from heating [57]. Enzymes, such as laccase, are sensitive to temperature, which affects not only its own conformation but also the enzyme-substrate interaction, and consequently the catalytic performance at elevated temperatures [2]. The thermal stability of laccase immobilized on CNTox-0.30 was evaluated and compared with the performance of the free enzyme, by running tests at three different temperatures, namely 40, 50 and $60^{\circ} \mathrm{C}$ (Fig. 4).

The experimental data followed an exponential decay model (Eq. 4). In this model, it is considered that the enzyme inactivation takes place in only one stage (the one-step transition between the active and denatured state) with the possibility of existing a remaining activity, represented by the parameter $\alpha$.

As expected, the increase in temperature leads to a decrease in the stability of the enzyme and reduction of its activity (Fig. 4). This inactivation is attributed to the increase in the vibration of the laccase structure when heated, that may lead to the breaking of chemical bonds and ultimately to a change in its 3D structure [9]. 

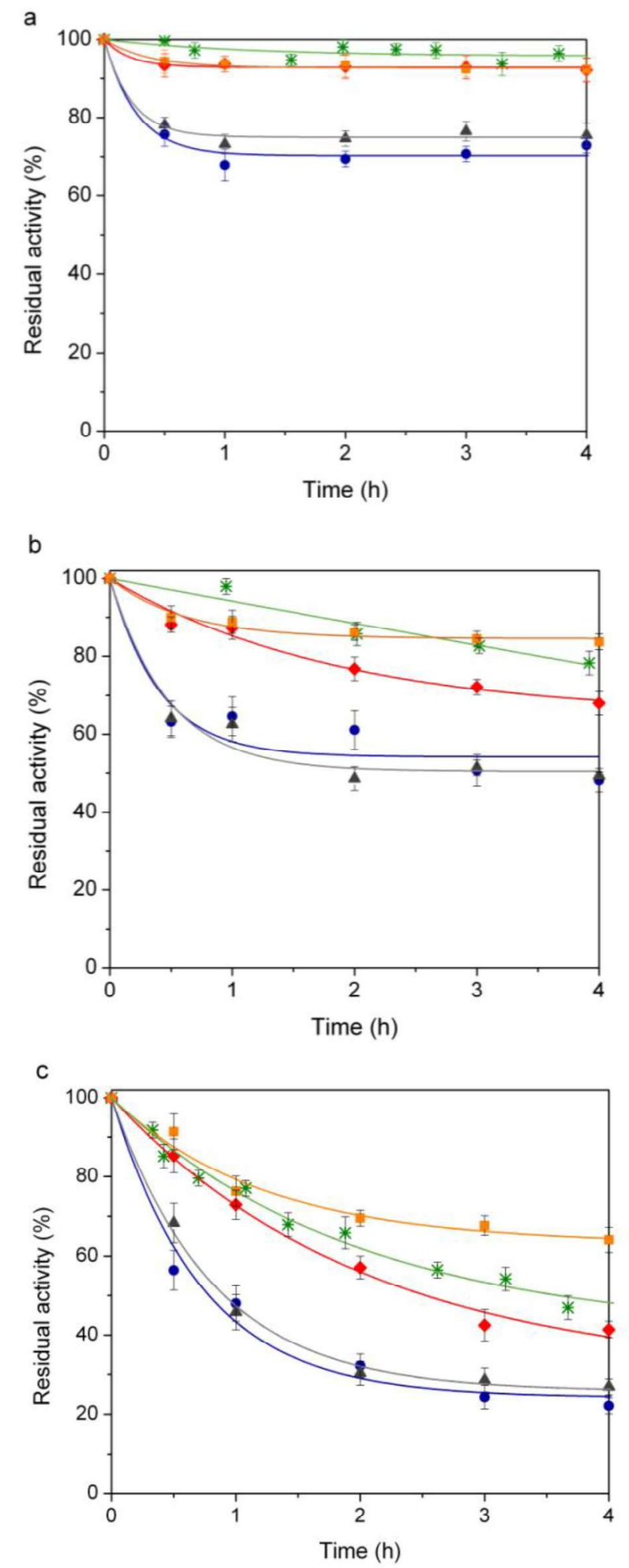

* free laccase $\bullet$ CNTox-0.30 $\Delta$ CNTox-0.30-G $\bullet$ CNTox-0.30-A $\approx$ CNTox-0.30-EN

Figure 4. Thermal inactivation of free and immobilized laccase, measured in terms of residual activity (\%) over a period of $4 \mathrm{~h}$, in phosphate buffer $(100 \mathrm{mM}, \mathrm{pH} 8.0)$ at temperatures of: (a) $40^{\circ} \mathrm{C}$; (b) $50 \mathrm{C}$; and (c) $60^{\circ} \mathrm{C}$. 
Overall, the most thermally stable system was the one based on CNTox-0.30-EN. For laccase immobilized in this material and incubated at $40{ }^{\circ} \mathrm{C}$, it can be observed that after a first rapid decay in the enzyme activity, the performance remained nearly constant (residual activity of c.a. 93\%). As the temperature increases, the residual activity decreases, being of $84 \%$ and $71 \%$ after $4 \mathrm{~h}$ of incubation for the tests performed at 50 and $60{ }^{\circ} \mathrm{C}$, respectively.

A good thermal stability was also obtained for the material functionalized with APTES. The thermal stability at $40^{\circ} \mathrm{C}$ is similar to laccase immobilized over CNTox0.30-EN but is relatively lower for the higher temperatures. These results suggest that the functionalization of CNTs with EDC/NHS and with APTES increase the stability of laccase when subjected to high temperature (between 40 and $60^{\circ} \mathrm{C}$ ) which may be attributed to a strong interaction between the enzyme and the support preventing thermal denaturation. It is worth noting, that at $60{ }^{\circ} \mathrm{C}$, the parameter $\alpha$ (remaining enzyme activity) is almost 2 times higher for CNTox-0.30-EN when compared with the other systems, confirming the enhanced performance of this material for laccase immobilization (Table 1).

Regarding the kinetics of laccase thermal inactivation, quantified by the kinetic rate constant $(k)$, it was observed that the initial inactivation of the bioconjugates was faster for lower temperatures. For instance, in the case of laccase immobilized over CNTox-0.30-EN, a kinetic deactivation constant of $2.71 \mathrm{~h}^{-1}$ was obtained for the reaction at $40{ }^{\circ} \mathrm{C}$, while the value decreases to 1.64 and $0.82 \mathrm{~h}^{-1}$ when the system was submitted a temperature of 50 and $60{ }^{\circ} \mathrm{C}$, respectively. Yet, after this initial inactivation phase, the enzymes retained their activity, as confirmed by the higher $\alpha$ values. In fact, the half-life $\left(t_{1 / 2}\right)$ could not be determined at 40 and $50{ }^{\circ} \mathrm{C}$ (except for free laccase at $50^{\circ} \mathrm{C}$ ) since the residual activity was kept above $50 \%$ 
during the biocatalytic runs (Figs. 4a-b). The same was observed when laccase was immobilized over CNTox-0.3-EN (Fig. 4c).

Table 1. Thermal stability kinetic parameters of free and immobilized laccase in phosphate buffer (100 mM, $\mathrm{pH} 8.0)$ at different temperatures over a period of $4 \mathrm{~h}$.

\begin{tabular}{|c|c|c|c|c|c|c|c|c|c|}
\hline \multirow{3}{*}{ Temperature } & \multicolumn{9}{|c|}{ Thermal parameters } \\
\hline & \multicolumn{3}{|c|}{$40^{\circ} \mathrm{C}$} & \multicolumn{3}{|c|}{$50^{\circ} \mathrm{C}$} & \multicolumn{3}{|c|}{$60^{\circ} \mathrm{C}$} \\
\hline & $\begin{array}{c}\alpha \\
(\%)\end{array}$ & $\begin{array}{c}k \\
\left(h^{-1}\right)\end{array}$ & $\begin{array}{l}t_{1 / 2} \\
\text { (h) }\end{array}$ & $\begin{array}{c}\alpha \\
(\%)\end{array}$ & $\begin{array}{c}k \\
\left(h^{-1}\right)\end{array}$ & $\begin{array}{l}t_{1 / 2} \\
\text { (h) }\end{array}$ & $\begin{array}{c}\alpha \\
(\%)\end{array}$ & $\begin{array}{c}k \\
\left(h^{-1}\right)\end{array}$ & $\begin{array}{l}t_{1 / 2} \\
\text { (h) }\end{array}$ \\
\hline Free laccase & - & - & $a$ & 32.0 & 0.09 & 14.4 & 26.5 & 0.36 & 3.16 \\
\hline CNTox-0.3 & 70.4 & 3.89 & $a$ & 54.1 & 2.44 & $a$ & 28.0 & 1.38 & 0.86 \\
\hline CNTox-0.3-G & 70.9 & 5.20 & $a$ & 50.4 & 2.10 & $a$ & 25.8 & 1.23 & 0.91 \\
\hline CNTox-0.3-A & 92.9 & 4.73 & $a$ & 64.6 & 0.54 & $a$ & 28.9 & 0.48 & 2.54 \\
\hline CNTox-0.3-EN & 92.7 & 2.71 & $a$ & 84.5 & 1.64 & $a$ & 63.0 & 0.82 & $a$ \\
\hline
\end{tabular}

${ }^{a}$ residual activity was kept above $50 \%$

The increase in thermal stability of laccase when the enzyme was immobilized over CNTox-0.30-EN may be attributed to the reduction in the enzyme structure mobility, due to its anchorage at the surface of the support [58].

\subsection{Operational stability of immobilized laccase}

One of the most important advantages of enzyme immobilization is the possibility to recover and reuse it in repeated catalytic cycles. The reutilization tests (Fig. 5) reveal that after 5 cycles of utilization, the highest activity was obtained for CNTox-0.30-EN. After 5 cycles, the enzyme immobilized on this material remained with $66 \%$ of its initial activity, contrasting with $38 \%, 29 \%$ and $18 \%$ obtained using CNTox-0.30-A, CNTox-0.30 and CNTox-0.30-G, respectively. 


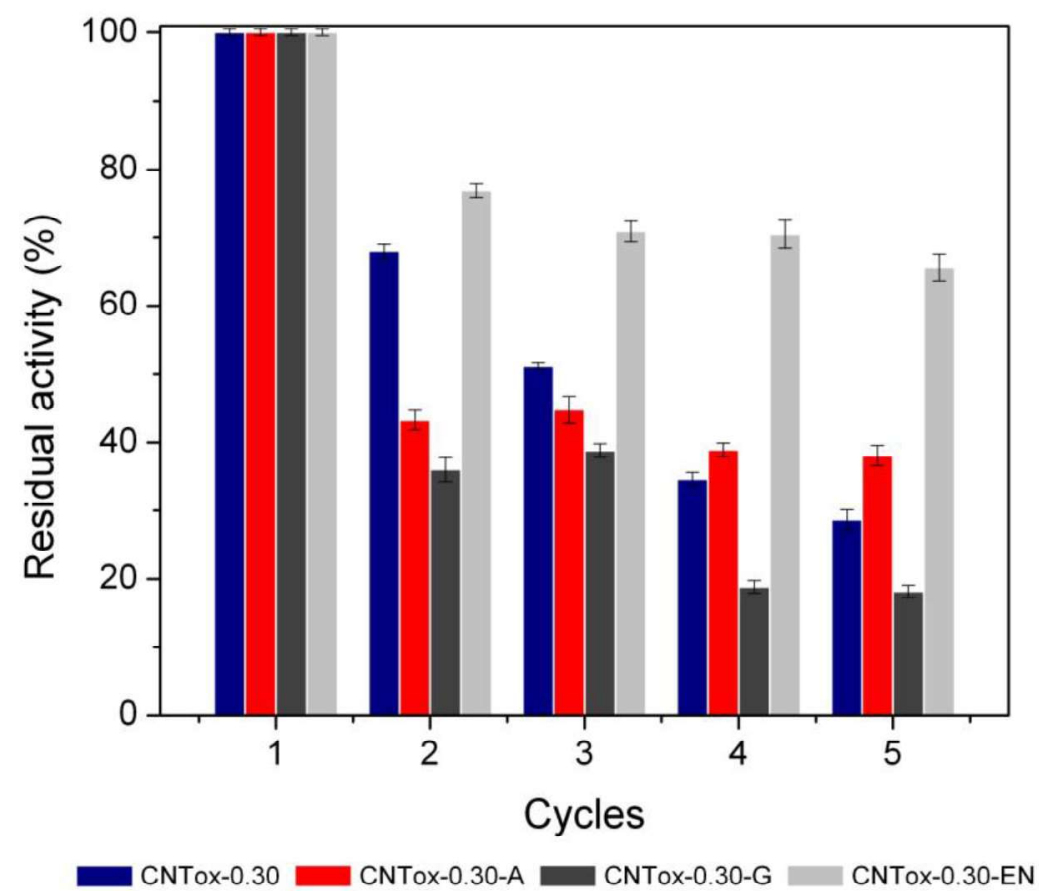

Figure 5. Residual immobilized laccase activity in 5 consecutive cycles of catalytic reaction. Experimental conditions: laccase immobilized in $50 \mathrm{mM}$ phosphate buffer (pH 8.0) under orbital stirring for $2 \mathrm{~h}$ at $25^{\circ} \mathrm{C}$.

The high activity loss of CNTox-0.30-G at the end of the first cycle (c.a. $64 \%$ ), is in line with the results obtained in the thermal stability study. The residual activity obtained using laccase immobilized over CNTox- 0.30 show a steady decline over the five cycles. Nevertheless, at the end of the first and second cycles, the enzymatic activity was higher comparing to CNTox- $0.30-\mathrm{G}$ and CNTox-0.30-A. For CNTox-0.30-A, although there is a high activity loss immediately after the first reuse (57\%), the enzyme activity remained nearly constant in the range $38-44 \%$ over the five cycles of reaction.

\subsection{Degradation of phenolic compounds using CNT/laccase bioconjugates}

Phenolic compounds may be found in variety effluents discharged from industrial and agricultural sources including olive oil and pulp mill wastewaters, 
wastes from coal conversion, manufacture of resins, plastics, adhesives, leather, among others. Conventional wastewater methods for treating phenolic effluents include biological treatment, adsorption, chemical oxidation such as ozonation and Fenton reaction, and photocatalytic processes [59]. However, these techniques are costly, time consuming, require metals, other chemicals, and may be inefficient for the removal of phenol. On the other hand, enzymatic wastewater treatment can be very efficient, due to the high degree of specificity of enzymes and because of the minimal environmental impact [60]. The best performing system, CNTox-0.30-EN, was selected for the treatment of an aqueous mixture containing four phenolic compounds normally used as model molecules because they are often present in many different effluents: phenol (PH), resorcinol (RS), 4-methoxyphenol (MP) and 4chlorophenol (CP) [61, 62].

The degradation of the phenolic compounds was firstly carried out using free laccase, both in the presence and absence of ABTS as enzyme mediator (Figs. 6a and b).

The parent $\mathrm{PH}$ is quite refractory to the action of the enzyme, even in the presence of ABTS, with less than $10 \%$ being removed at the end of $60 \mathrm{~min}$ of reaction. RS was hardly degraded by laccase in the absence of the mediator. Nevertheless, it was almost totally degraded by the laccase mediator system (94\% removal) after $1 \mathrm{~h}$. In the case of $\mathrm{CP}$, the presence of ABTS led to an increase in degradation from 22 to $41 \%$. MP was the most easily degraded compound with total removal being achieved at the end of the reaction even in the absence of ABTS and at the end of merely 5 min using the laccase mediator.

The enhanced catalytic efficiency of laccase in the presence of ABTS results from the mediating role of ABTS which acts as an "electron shuttle", i.e. the oxidized 
ABTS diffuses away from the enzyme and oxidizes substrate by the removal of one electron from the substrate [63]. The rate of electron transfer from the substrate to the T1 copper in the active site of laccase is usually considered as the rate-limiting step, depending on the $\Delta E^{0}$ between the T1 copper and the substrate $[64,65]$. Moreover, because all the phenolic compounds investigated behave as substrates for laccase, competitive effects may arise when treating the multi-component solution, resulting in a poor removal of each compound individually. In fact, a control experiment was performed using laccase/ABTS system for the degradation of phenol in aqueous medium and $90 \%$ removal of this compound was achieved at the end of $60 \mathrm{~min}$ of reaction (see Supplementary Information. Fig. SI4), contrasting with the ca. 10\% during the catalytic treatment of the mixture of phenolic compounds (Fig. 6b).

The molecules structure and redox potential of laccase $(500-800 \mathrm{mV})$ strongly influences the power to oxidize each of the compounds in the mixture [66]. In fact, MP, which has the lowest redox potential $(540 \mathrm{mV})$, was the easiest to oxidize, while $\mathrm{PH}$ and $\mathrm{CP}$ with redox potentials of c.a. $800 \mathrm{mV}$ were the most refractory ones [67]. 

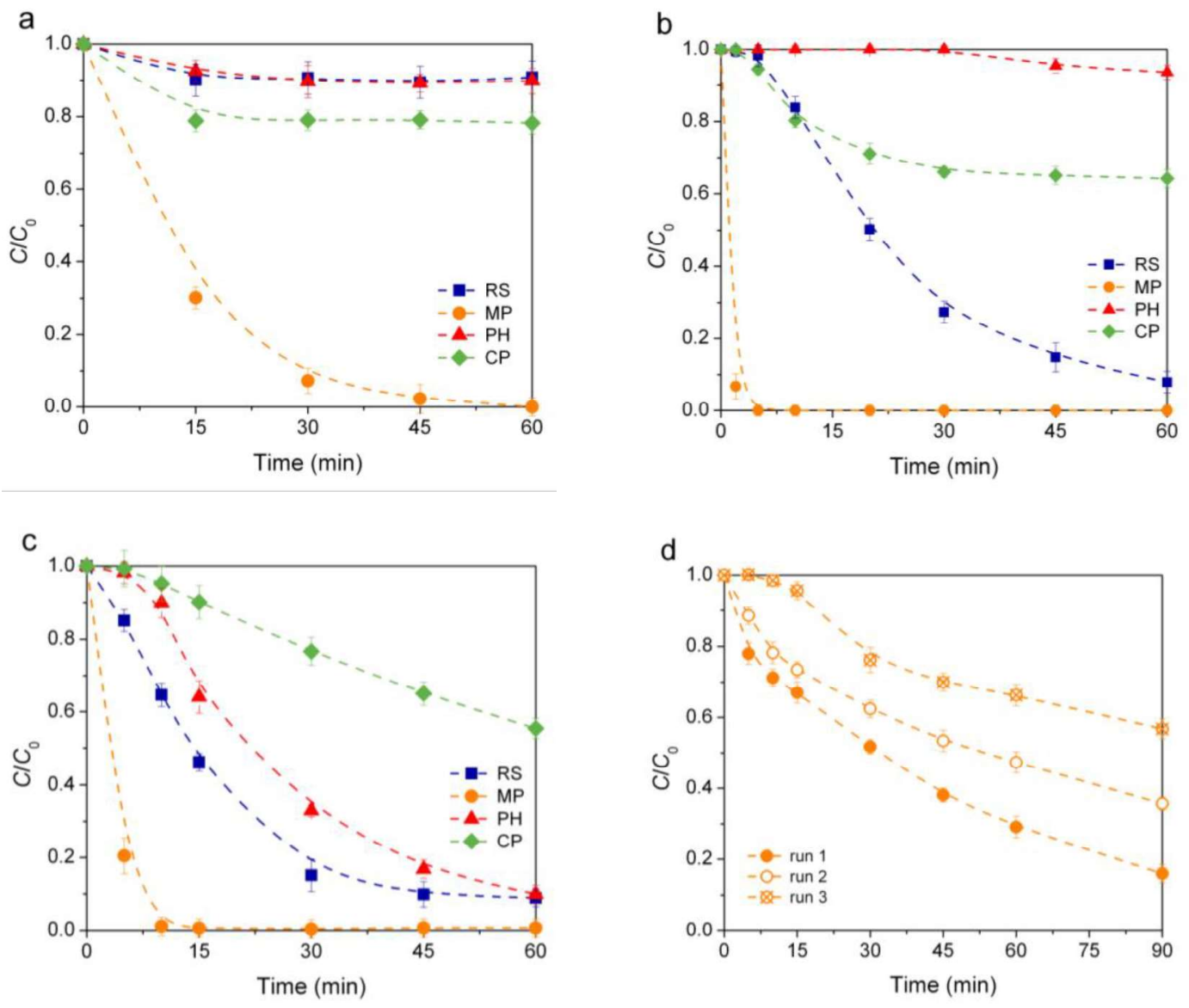

e<smiles>Oc1cccc(O)c1</smiles>

$$
\text { RS }
$$

Resorcinol<smiles>COc1ccc(O)cc1</smiles>

MP

4-methoxyphenol<smiles>Oc1ccccc1</smiles>

$\mathrm{PH}$

Phenol<smiles>Oc1ccc(Cl)cc1</smiles>

Figure 6. Degradation of a mixture of phenolic compounds over $60 \mathrm{~min}$ runs in the presence of: (a) free laccase with no mediator; (b) free laccase in the presence of ABTS as mediator; (c) laccase immobilized over CNTox-0.30-EN in the presence of ABTS as mediator; (d) utilization of laccase/CNTox-0.30-EN in 3 consecutive cycles for the degradation of MP with no mediator over $90 \mathrm{~min}$; and (e) chemical structures of PH - phenol; RS - resorcinol; MP - 4-methoxyphenol and CP - 4-chlorophenol. Experimental conditions: reactions using $20 \mathrm{~mL}$ of aqueous solutions containing 10 $\mathrm{mg} \mathrm{\textrm {L } ^ { - 1 }} \mathrm{MP}$ or a mixture of phenolics with a concentration of $10 \mathrm{mg} \mathrm{L}^{-1}$ in each component, at natural $\mathrm{pH}$ (5.6). 
Regarding the reaction using laccase immobilized over CNTox-0.30-EN and ABTS as mediator, a different behavior was observed. Starting with the parent $\mathrm{PH}$, a $90 \%$ removal was achieved (from the mixture of phenols) at the end of 60 min of reaction contrasting with the $10 \%$ registered using the free enzyme.

A control experiment to assess the possibility of adsorption was performed by suspending CNTox-0.30-EN in the mixture of phenolic compounds (see Supplementary Supporting Information, Fig. SI5). Typically, the adsorption of phenol derivatives over CNTs is not significant, the degree of such being dependent on the functionalization of the surface. The removal of each phenolic compound over CNTs at the end of 60 min of contact followed the order: CP (17\%), MP (10\%), RS (5\%) and $\mathrm{PH}(4 \%)$. These results indicate that adsorption is not likely to be the main active mechanism, showing how crucial the presence of enzyme is for the degradation process. In the biocatalytic process, MP was the most easily removed compound, with total degradation (100\%) being achieved at the end of only $5 \mathrm{~min}$ and $10 \mathrm{~min}$ for free and immobilized laccase on CNTox-0.30-EN, respectively, in the presence of ABTS as enzyme mediator (Fig. 6b and 6c). The slower degradation of MP by laccase immobilized over CNTs when compared with the reaction using the free enzyme may be attributed to mass-transfer limitations, because of internal diffusion restrains since the substrate (MP) may not reach the active part of the immobilized enzyme. This behavior has been observed in other studies using immobilized enzymes [68, 69]. Yet, from both technological and economic standpoints, the use of the immobilized enzyme is always preferable due to the possibility of reutilization.

The kinetics of RS degradation using laccase in the free and immobilized forms are similar, while $\mathrm{CP}$ removal was slower but varying steadily during the reaction time. 
Reuse tests were performed for MP removal using laccase immobilized over CNTox-0.30-EN in the absence of ABTS (Fig. 6d). As expected, MP was easily degraded in the absence of the mediator, attaining $84 \%$ of removal in 90 min of reaction. However, a progressive loss in enzyme activity was observed for the second and third utilizations of the laccase/CNTox-0.30-EN conjugate, probably due to the blockage of the active sites by MP or by degradation products.

\subsection{Degradation of phenolic compounds using bio-catalytic CNT/PSf/laccase membranes}

Enzymatic processes should possess cost-effectiveness and high productivity of the biocatalyst [70]. The enzyme immobilization on membranes provides a more easy, economical and fast enzyme recovery when compared to CNT powders solely. Therefore, considering the promising results obtained with the direct laccase immobilized over CNTox-0.30-EN, PSf membranes blended with different amounts of these functionalized CNTs $(0.1,0.3$ and $0.5 \mathrm{wt} . \%)$ were developed and studied for laccase immobilization envisaging their fast and easy recovery and reuse. The immobilization of laccase was successfully achieved for all prepared CNT/M membranes regardless of the CNT-0.30-EN content (Table 2). In fact, different amounts of CNTox-0.30-EN into the membrane had a negligible effect on enzyme immobilization yield, a similar high capacity of immobilization being observed for all membranes evaluated $(\cong 91 \pm 1 \%)$ and being comparable to the immobilization yield of laccase on CNTs solely. In terms of enzyme activity, the bio-catalytic performance of the membranes was affected by the CNT content (Table 2), the membrane containing 0.1 wt. $\%$ of CNTox-0.30-EN (0.1-CNT/M) presenting the highest activity (12663 U/g $\mathrm{CNT}$ into membrane). 
Table 2. Results of laccase immobilization on PSf membranes containing different amounts of CNTox-0.3-EN.

\begin{tabular}{lcc}
\hline Membrane & $\begin{array}{c}\text { Immobilization yield } \\
\mathbf{( \% )}\end{array}$ & $\begin{array}{c}\text { Laccase activity } \\
\left(\mathbf{U} / \mathbf{g}^{*}\right)\end{array}$ \\
\hline $0.1-\mathrm{CNT} / \mathrm{M}$ & $89.8 \pm 5.4$ & $12663 \pm 340$ \\
$0.3-\mathrm{CNT} / \mathrm{M}$ & $92.0 \pm 7.2$ & $8620 \pm 54$ \\
$0.5-\mathrm{CNT} / \mathrm{M}$ & $92.0 \pm 6.3$ & $3278 \pm 23$ \\
\hline
\end{tabular}

$* \mathrm{U} / \mathrm{g}_{\mathrm{CNT}}$ into membrane

All these bio-catalytic membranes were selected to evaluate their performance in a real application. MP was chosen since this compound was easily removed by laccase, as presented above. Thus, the degradation of MP was studied with CNT/M membranes and compared to those obtained for the neat PSf membrane (M) and also using the CNTox-0.30-EN nanomaterial. In general, MP was fast degraded in 15 min for all membranes containing functionalized CNTs (Fig. 7a), being their performance superior to that obtained for the neat PSf membrane (ca. $85 \%$ MP conversion for 60 min). Furthermore, $\mathrm{CNT} / \mathrm{M}$ membranes presented different laccase activities, being the best result obtained for the membranes containing the lowest CNT content (Table 2). Regarding MP removal, some differences can be observed during several degradation cycles. In general, all CNT/M membranes lost the MP removal efficiency after 3 cycles of reuse, while the M membrane lost that after 2 cycles (Fig 7a). The low efficiency on MP degradation observed for all membranes after consecutive cycles should be again due to some loss of enzyme or blockage of the active sites. Considering the reutilization ability of the membranes, the enzyme was reimmobilized over the spent membranes. The results presented in Fig. $7 \mathrm{~b}$ show the 
potential of re-utilization of the membranes for a new enzyme loading. Moreover, the highest capacity for MP degradation was observed for CNT/M membranes, in particular for 0.1-CNT/M, the membrane with the best performance. Nevertheless, the possibility of reuse the enzyme can be considered a great advantage at both economic and technological standpoints.
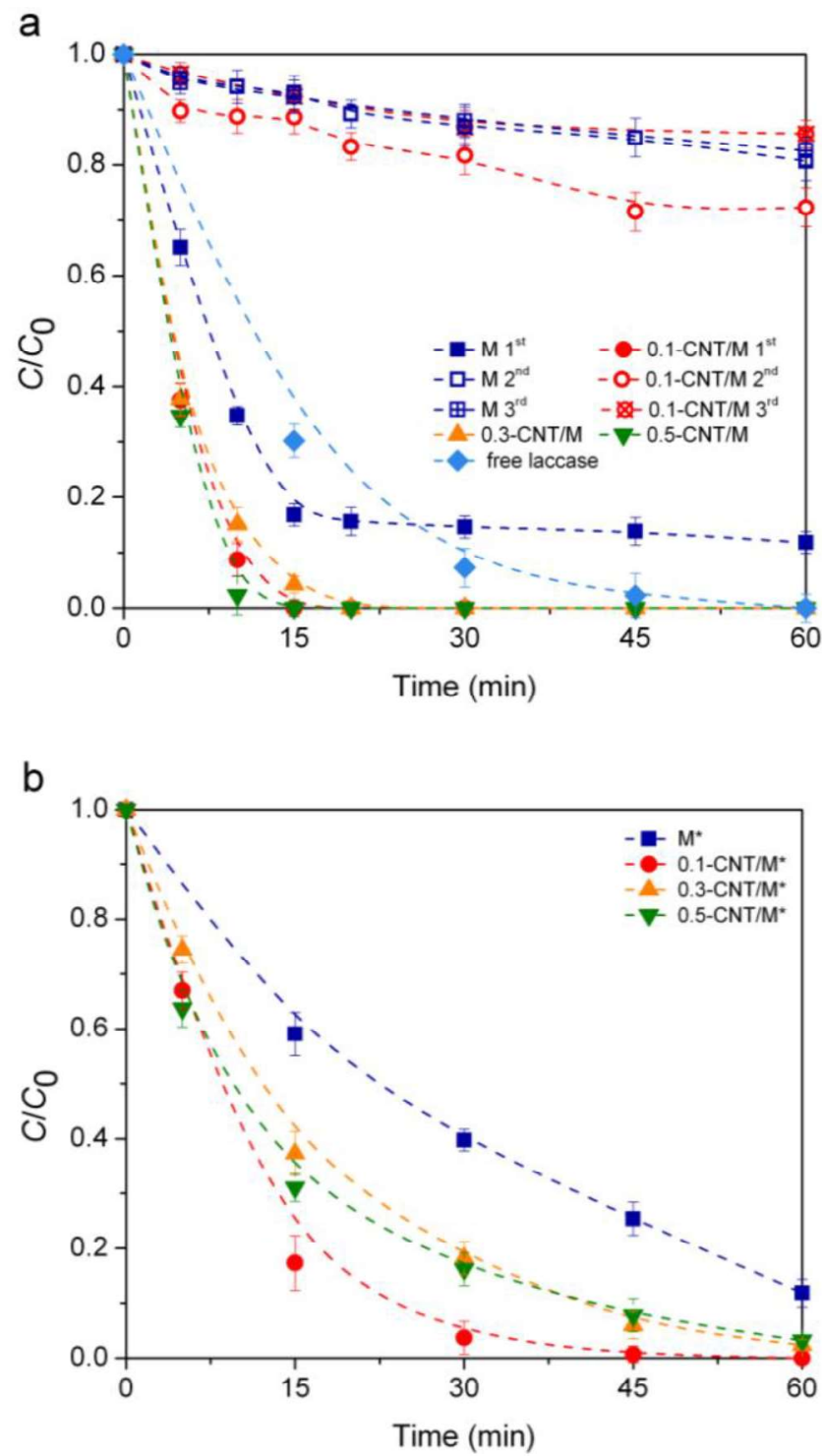

Figure 7. (a) Degradation of MP using laccase immobilized over the different PSf membranes, the $2^{\text {nd }}$ and $3^{\text {rd }}$ utilizations for $\mathrm{M}$ and $0.1-\mathrm{CNT} / \mathrm{M}$ are also included for comparison; (b) degradation of MP using a second immobilization of laccase on used 
PSf membranes (M*). Experimental conditions: reactions using $20 \mathrm{~mL}$ of $10 \mathrm{mg} \mathrm{L} \mathrm{L}^{-1}$ MP aqueous solutions at natural $\mathrm{pH}$ (5.6).

In general, the properties of supported enzymes reflect not only the properties of the combined materials, but also the result of interaction between both, which can be potentially synergetic. The results here presented show not only the advantages of using a somewhat rigid material but provide an additional indication of the strategies to tailor the material at the enzyme needs. Optimization of the functionalization of the CNTs carriers is the next step of this work. A material like CNTs provides the mechanical strength normally required to expand these applications to real industrial processes, as opposition to the well spread supporting matrixes based on soft gels.

\section{Conclusions}

Laccase can be efficiently immobilized over multi-walled carbon nanotubes or membranes. Higher immobilization efficiency and recovered activity was obtained using CNTs oxidized with $\mathrm{HNO}_{3} 0.30 \mathrm{M}(\mathrm{CNT}$ ox-0.30), which is related to the higher number of oxygen-containing groups available at the surface of the material.

The system CNTox-0.30-EN possesses the best compromise between immobilization efficiency (100\%), and recovered activity (20.5\%), being also the most stable material at higher temperatures.

The laccase/CNTox-0.30-EN kept its high performance in 5 consecutive utilizations for the oxidation of ABTS. The enhanced performance of CNTox-0.30EN can be attributed to strong linkage between the enzyme and the supporting material. 
The laccase/CNTox-0.30-EN bioconjugate was successfully used for the treatment of a mixture of four phenolic compounds, the process showing similar efficiency as the analogous using the free enzyme, with the possibility of reusing the biocatalyst.

PSf membranes containing functionalized CNTs demonstrated to be also an excellent support for the enzyme (re)-immobilization and their application in the degradation of 4-methoxiphenol. The PSf membrane with 0.1 wt.\% of CNTox-0.30EN was the most efficient, presenting a comparable activity to CNTs solely and with a much lower CNT content.

In summary, the results here presented validate the immobilization capacity and bio-catalytic performance of laccase on CNTs and CNT-based membranes as a technological solution in all the fields of its application. Particularly for membrane technologies, the savings on cost and the potential of combination with membrane separation functions will bring opportunities at industrial level.

\section{Acknowledgements}

This work was financially supported by Projects POCI-01-0145-FEDER-006984 Associate Laboratory LSRE-LCM and POCI-01-0145-FEDER-031268 funded by FEDER through COMPETE2020 - Programa Operacional Competitividade e Internacionalização (POCI) - and by national funds and by national funds (OE), through FCT/MCTES - Fundação para a Ciência e a Tecnologia. The work was developed in the scope of the project CICECO-Aveiro Institute of Materials (Ref. FCT UID/CTM/50011/2013), financed by national funds through the FCT/MEC and co-financed by FEDER under the PT2020 Partnership Agreement. M.C.N. acknowledges FCT the post-doctoral grants SFRH/BPD/110423/2015. M.J.L. acknowledges FCT for the research grant PD/BD/52623/2014, while C.G.S. and 
M.J.S. acknowledge the FCT Investigator Programme (IF/00514/2014) with financing from the European Social Fund and the Human Potential Operational Programme. A.P.M. Tavares acknowledges FCT for the research contract under the IF (IF/01634/2015) Investigator Programme-2015. S.M.T. acknowledges the financial support from the University of Granada, Programme: "Proyectos de Investigación para la Incorporación de Jóvenes Doctores". We are indebted to Dr. Carlos Sá and the CEMUP team (Portugal) for technical assistance and advice with SEM/EDXS measurements.

\section{References}

[1] A.A. Homaei, R. Sariri, F. Vianello, R. Stevanato, Enzyme immobilization: An update, J. Chem. Biol. 6 (2013) 185-205.

[2] R.O. Cristóvão, A.P.M. Tavares, A.I. Brígida, J.M. Loureiro, R.A.R. Boaventura, E.A. Macedo, M.A.Z. Coelho, Immobilization of commercial laccase onto green coconut fiber by adsorption and its application for reactive textile dyes degradation, $\mathrm{J}$. Mol. Catal. B: Enzym. 72 (2011) 6-12.

[3] Q. Husain, Potential applications of the oxidoreductive enzymes in the decolorization and detoxification of textile and other synthetic dyes from polluted water: A review, Crit. Rev. Biotechnol. 26 (2006) 201-221.

[4] C. López, I. Mielgo, M.T. Moreira, G. Feijoo, J.M. Lema, Enzymatic membrane reactors for biodegradation of recalcitrant compounds. Application to dye decolourisation, J. Biotechnol. 99 (2002) 249-257.

[5] R. Xu, R. Tang, Q. Zhou, F. Li, B. Zhang, Enhancement of catalytic activity of immobilized laccase for diclofenac biodegradation by carbon nanotubes, Chem. Eng. J. 262 (2015) 88-95.

[6] T.A. Nguyen, C.-C. Fu, R.-S. Juang, Effective removal of sulfur dyes from water by biosorption and subsequent immobilized laccase degradation on crosslinked chitosan beads, Chem. Eng. J. 304 (2016) 313-324.

[7] S. Datta, L.R. Christena, Y.R.S. Rajaram, Enzyme immobilization: an overview on techniques and support materials, 3 Biotech 3 (2013) 1-9. 
[8] X.-L. Xie, Y.-W. Mai, X.-P. Zhou, Dispersion and alignment of carbon nanotubes in polymer matrix: A review, Mater. Sci. Eng., R 49 (2005) 89-112.

[9] C.G. Silva, A.P.M. Tavares, G. Dražić, A.M.T. Silva, J.M. Loureiro, J.L. Faria, Controlling the Surface Chemistry of Multiwalled Carbon Nanotubes for the Production of Highly Efficient and Stable Laccase-Based Biocatalysts, ChemPlusChem 79 (2014) 1116-1122.

[10] Y. Amano, A. Koto, S. Matsuzaki, H. Sakamoto, T. Satomura, S.I. Suye, Construction of a biointerface on a carbon nanotube surface for efficient electron transfer, Mater. Lett. 174 (2016) 184-187.

[11] Y. Fan, G. Wu, F. Su, K. Li, L. Xu, X. Han, Y. Yan, Lipase orientedimmobilized on dendrimer-coated magnetic multi-walled carbon nanotubes toward catalyzing biodiesel production from waste vegetable oil, Fuel 178 (2016) 172-178.

[12] S. Gupta, C.R. Prabha, C.N. Murthy, Functionalized multi-walled carbon nanotubes/polyvinyl alcohol membrane coated glassy carbon electrode for efficient enzyme immobilization and glucose sensing, J. Environ. Chem. Eng. 4 (2016) 37343740 .

[13] C. Ji, J. Hou, V. Chen, Cross-linked carbon nanotubes-based biocatalytic membranes for micro-pollutants degradation: Performance, stability, and regeneration, J. Membr. Sci. 520 (2016) 869-880.

[14] H. Bisswanger, Enzyme assays, Perspect. Sci. 1 (2014) 41-55.

[15] W. Feng, P. Ji, Enzymes immobilized on carbon nanotubes, Biotechnol. Adv. 29 (2011) 889-895.

[16] Y. Wang, H. Xu, Z. Wang, R. Hu, Z. Luo, Z. Xu, G. Li, A Glucose sensor based on glucose oxidase immobilized by electrospinning nanofibrous polymer membranes modified with carbon nanotubes, Sens. Transducers 152 (2013) 180-185.

[17] Y. Dai, J. Yao, Y. Song, X. Liu, S. Wang, Y. Yuan, Enhanced performance of immobilized laccase in electrospun fibrous membranes by carbon nanotubes modification and its application for bisphenol A removal from water, J. Hazard. Mater. 317 (2016) 485-493.

[18] Y. Dai, J. Yao, Y. Song, S. Wang, Y. Yuan, Enhanced adsorption and degradation of phenolic pollutants in water by carbon nanotube modified laccasecarrying electrospun fibrous membranes, Environ. Sci.: Nano 3 (2016) 857-868.

[19] A.M. Othman, E. González-Domínguez, Á. Sanromán, M. Correa-Duarte, D. Moldes, Immobilization of laccase on functionalized multiwalled carbon nanotube 
membranes and application for dye decolorization, RSC Adv. 6 (2016) 114690114697.

[20] S. Morales-Torres, C.M.P. Esteves, J.L. Figueiredo, A.M.T. Silva, Thin-film composite forward osmosis membranes based on polysulfone supports blended with nanostructured carbon materials, J. Membr. Sci. 520 (2016) 326-336.

[21] A. Messerschmidt, R. Huber, The blue oxidases, ascorbate oxidase, laccase and ceruloplasmin Modelling and structural relationships, Eur. J. Biochem. 187 (1990) 341-352.

[22] V. Madhavi, S.S. Lele, Laccase: Properties and applications, BioResources 4 (2009) 1694-1717.

[23] K. Piontek, M. Antorini, T. Choinowski, Crystal Structure of a Laccase from the FungusTrametes versicolor at 1.90- $\AA$ Resolution Containing a Full Complement of Coppers, J. Biol. Chem. 277 (2002) 37663-37669.

[24] G.T.R. Palmore, H.-H. Kim, Electro-enzymatic reduction of dioxygen to water in the cathode compartment of a biofuel cell, J. Electroanal. Chem. 464 (1999) 110-117. [25] F. Trudeau, F. Daigle, D. Leech, Reagentless Mediated Laccase Electrode for the Detection of Enzyme Modulators, Anal. Chem. 69 (1997) 882-886.

[26] R.O. Cristóvão, A.P.M. Tavares, A.S. Ribeiro, J.M. Loureiro, R.A.R. Boaventura, E.A. Macedo, Kinetic modelling and simulation of laccase catalyzed degradation of reactive textile dyes, Bioresour. Technol. 99 (2008) 4768-4774.

[27] R.O. Cristovao, A.P. Tavares, L.A. Ferreira, J.M. Loureiro, R.A. Boaventura, E.A. Macedo, Modeling the discoloration of a mixture of reactive textile dyes by commercial laccase, Bioresour. Technol. 100 (2009) 1094-1099.

[28] G. Busca, S. Berardinelli, C. Resini, L. Arrighi, Technologies for the removal of phenol from fluid streams: A short review of recent developments, J. Hazard. Mater. 160 (2008) 265-288.

[29] C. Hoffmann, H. Silau, M. Pinelo, J.M. Woodley, A.E. Daugaard, Surface modification of polysulfone membranes applied for a membrane reactor with immobilized alcohol dehydrogenase, Mater. Today Commun. 14 (2018) 160-168.

[30] Y. Guo, X. Zhu, F. Fang, X. Hong, H. Wu, D. Chen, X. Huang, Immobilization of enzymes on a phospholipid bionically modified polysulfone gradient-pore membrane for the enhanced performance of enzymatic membrane bioreactors, Molecules 23 (2018). 
[31] X.Y. Zhu, C. Chen, P.C. Chen, Q.L. Gao, F. Fang, J. Li, X.J. Huang, Highperformance enzymatic membrane bioreactor based on a radial gradient of pores in a PSF membrane via facile enzyme immobilization, RSC Adv. 6 (2016) 30804-30812.

[32] F. Yasar Mahlicli, Y. en, M. Mutlu, S. Alsoy Altinkaya, Immobilization of superoxide dismutase/catalase onto polysulfone membranes to suppress hemodialysisinduced oxidative stress: A comparison of two immobilization methods, J. Membr. Sci. 479 (2015) 175-189.

[33] A.P.M. Tavares, C.G. Silva, G. Dražić, A.M.T. Silva, J.M. Loureiro, J.L. Faria, Laccase immobilization over multi-walled carbon nanotubes: Kinetic, thermodynamic and stability studies, J. Colloid Interface Sci. 454 (2015) 52-60.

[34] P. Ander, K. Messner, Oxidation of 1-hydroxybenzotriazole by laccase and lignin peroxidase, Biotechnol. Tech. 12 (1998) 191-195.

[35] M. Arroyo, J.M. Sanchez-Montero, J.V. Sinisterra, Thermal stabilization of immobilized lipase B from Candida antarctica on different supports: Effect of water activity on enzymatic activity in organic media, Enzyme Microb. Technol. 24 (1999) 3-12.

[36] J.P. Henley, A. Sadana, Categorization of enzyme deactivations using a seriestype mechanism, Enzyme Microb. Technol. 7 (1985) 50-60.

[37] J. Chen, Q. Chen, Q. Ma, Influence of surface functionalization via chemical oxidation on the properties of carbon nanotubes, J. Colloid Interface Sci. 370 (2012) $32-38$

[38] S. Sam, L. Touahir, J. Salvador Andresa, P. Allongue, J.N. Chazalviel, A.C. Gouget-Laemmel, C. Henry de Villeneuve, A. Moraillon, F. Ozanam, N. Gabouze, S. Djebbar, Semiquantitative Study of the EDC/NHS Activation of Acid Terminal Groups at Modified Porous Silicon Surfaces, Langmuir 26 (2009) 809-814.

[39] H. Fabian, W. Mäntele, J.M. Chalmers, Infrared Spectroscopy of Proteins, in: J.M. Chalmers, P.R. Griffiths (Eds.) Handbook of Vibrational Spectroscopy, John Wiley \& Sons, 2006.

[40] P.V. Iyer, L. Ananthanarayan, Enzyme stability and stabilization-Aqueous and non-aqueous environment, Process Biochem. 43 (2008) 1019-1032.

[41] M. El-Sherbiny, G. El-Chaghaby, Storage temperature and stabilizers in relation to the activity of commercial liquid feed enzymes: a case study from Egypt, J. Agrobiol. 28 (2011). 
[42] L. Otubo, O. Ferreira, A. Filho, O. Alves, Raman spectroscopy for probing covalent functionalization of single-wall carbon nanotubes bundles with gold nanoparticles, J. Nanopart. Res. 16 (2014) 1-12.

[43] K. Matsuura, T. Saito, T. Okazaki, S. Ohshima, M. Yumura, S. Iijima, Selectivity of water-soluble proteins in single-walled carbon nanotube dispersions, Chem. Phys. Lett. 429 (2006) 497-502.

[44] S.S. Karajanagi, A.A. Vertegel, R.S. Kane, J.S. Dordick, Structure and Function of Enzymes Adsorbed onto Single-Walled Carbon Nanotubes, Langmuir 20 (2004) 11594-11599.

[45] R.M. Azevedo, J.B. Costa, P. Serp, J.M. Loureiro, J.L. Faria, C.G. Silva, A.P.M. Tavares, A strategy for improving peroxidase stability via immobilization on surface modified multi-walled carbon nanotubes, J. Chem. Technol. Biotechnol. 90 (2015) $1570-1578$.

[46] R.R.N. Marques, B.F. Machado, J.L. Faria, A.M.T. Silva, Controlled generation of oxygen functionalities on the surface of Single-Walled Carbon Nanotubes by HNO3 hydrothermal oxidation, Carbon 48 (2010) 1515-1523.

[47] J.L. Figueiredo, M.F.R. Pereira, M.M.A. Freitas, J.J.M. Órfão, Characterization of Active Sites on Carbon Catalysts, Ind. Eng. Chem. 46 (2007) 4110-4115.

[48] J. Kulys, R. Vidziunaite, P. Schneider, Laccase-catalyzed oxidation of naphthol in the presence of soluble polymers, Enzyme Microb. Technol. 32 (2003) 455-463.

[49] M. Monthioux, B.W. Smith, B. Burteaux, A. Claye, J.E. Fischer, D.E. Luzzi, Sensitivity of single-wall carbon nanotubes to chemical processing: an electron microscopy investigation, Carbon 39 (2001) 1251-1272.

[50] S.K. Vashist, E. Lam, S. Hrapovic, K.B. Male, J.H.T. Luong, Immobilization of Antibodies and Enzymes on 3-Aminopropyltriethoxysilane-Functionalized Bioanalytical Platforms for Biosensors and Diagnostics, Chem. Rev. 114 (2014) 11083-11130.

[51] C. Silva, C.J. Silva, A. Zille, G.M. Guebitz, A. Cavaco-Paulo, Laccase immobilization on enzymatically functionalized polyamide 6,6 fibres, Enzyme Microb. Technol. 41 (2007) 867-875.

[52] F.H. Isgrove, R.J.H. Williams, G.W. Niven, A.T. Andrews, Enzyme immobilization on nylon-optimization and the steps used to prevent enzyme leakage from the support, Enzyme Microb. Technol. 28 (2001) 225-232. 
[53] F. Vaillant, A. Millan, P. Millan, M. Dornier, M. Decloux, M. Reynes, Coimmobilized pectinlyase and endocellulase on chitin and Nylon supports, Process Biochem. 35 (2000) 989-996.

[54] N. Alonso, F. López-Gallego, L. Betancor, A. Hidalgo, C. Mateo, J.M. Guisan, R. Fernandez-Lafuente, Immobilization and stabilization of glutaryl acylase on aminated sepabeads supports by the glutaraldehyde crosslinking method, J. Mol. Catal. B: Enzym. 35 (2005) 57-61.

[55] J.V. Staros, R.W. Wright, D.M. Swingle, Enhancement by Nhydroxysulfosuccinimide of water-soluble carbodiimide-mediated coupling reactions, Anal. Biochem. 156 (1986) 220-222.

[56] D. Sehgal, I.K. Vijay, A Method for the High Efficiency of Water-Soluble Carbodiimide-Mediated Amidation, Anal. Biochem. 218 (1994) 87-91.

[57] M.-Y. Chang, R.-S. Juang, Use of chitosan-clay composite as immobilization support for improved activity and stability of $\beta$-glucosidase, Biochem. Eng. J. 35 (2007) 93-98.

[58] M.L. Verma, M. Naebe, C.J. Barrow, M. Puri, Enzyme Immobilisation on Amino-Functionalised Multi-Walled Carbon Nanotubes: Structural and Biocatalytic Characterisation, PLoS ONE 8 (2013) e73642.

[59] L.G.C. Villegas, N. Mashhadi, M. Chen, D. Mukherjee, K.E. Taylor, N. Biswas, A Short Review of Techniques for Phenol Removal from Wastewater, Curr. Pollut. Rep. 2 (2016) 157-167.

[60] M. Gomez, G. Matafonova, J.L. Gomez, V. Batoev, N. Christofi, Comparison of alternative treatments for 4-chlorophenol removal from aqueous solutions: Use of free and immobilized soybean peroxidase and $\mathrm{KrCl}$ excilamp, J. Hazard. Mater. 169 (2009) 46-51.

[61] S. Ahmed, M.G. Rasul, R. Brown, M.A. Hashib, Influence of parameters on the heterogeneous photocatalytic degradation of pesticides and phenolic contaminants in wastewater: A short review, J. Environ. Manage. 92 (2011) 311-330.

[62] M.J. Sampaio, C.G. Silva, A.M. Silva, V.J. Vilar, R.A. Boaventura, J.L. Faria, Photocatalytic activity of Tio2-coated glass raschig rings on the degradation of phenolic derivatives under simulated solar light irradiation, Chem. Eng. J. 224 (2013) 32-38. 
[63] B. Branchi, C. Galli, P. Gentili, Kinetics of oxidation of benzyl alcohols by the dication and radical cation of ABTS. Comparison with laccase-ABTS oxidations: an apparent paradox, Org. Biomol. Chem. 3 (2005) 2604-2614.

[64] F. Xu, Oxidation of Phenols, Anilines, and Benzenethiols by Fungal Laccases: Correlation between Activity and Redox Potentials as Well as Halide Inhibition, Biochemistry 35 (1996) 7608-7614.

[65] F. Xu, Effects of Redox Potential and Hydroxide Inhibition on the $\mathrm{pH}$ Activity Profile of Fungal Laccases, J. Biol. Chem. 272 (1997) 924-928.

[66] L. Gianfreda, F. Sannino, M.A. Rao, J.M. Bollag, Oxidative transformation of phenols in aqueous mixtures, Water Res. 37 (2003) 3205-3215.

[67] C. Johannes, A. Majcherczyk, Natural mediators in the oxidation of polycyclic aromatic hydrocarbons by laccase mediator systems, Appl. Environ. Microbiol. 66 (2000) 524-528.

[68] I. Ardao, G. Alvaro, M.D. Benaiges, Reversible immobilization of rhamnulose-1phosphate aldolase for biocatalysis: Enzyme loading optimization and aldol addition kinetic modeling, Biochem. Eng. J. 56 (2011) 190-197.

[69] W.E. Berendsen, A. Lapin, M. Reuss, Investigations of reaction kinetics for immobilized enzymes - Identification of parameters in the presence of diffusion limitation, Biotechnol. Progr. 22 (2006) 1305-1312.

[70] P. Tufvesson, J. Lima-Ramos, M. Nordblad, J.M. Woodley, Guidelines and Cost Analysis for Catalyst Production in Biocatalytic Processes, Org. Process Res. Dev. 15 (2011) 266-274. 
